\title{
Surdocegueira, Cartografia e Decolonialidade
}

\author{
Arheta Ferreira de Andrade \\ Instituto Benjamin Constant, RJ, Brasil.
}

Resumo: O presente artigo é composto de parte de minha pesquisa de doutorado, cujo propósito foi buscar interfaces entre os campos da Surdocegueira e da Arte. O trabalho foi desenvolvido com pessoas surdocegas, seus familiares e profissionais do Programa de Atendimento e Apoio ao Surdocego (PAAS), do Instituto Benjamin Constant, situado no Rio de Janeiro. Através do método da cartografia, a pesquisa acompanhou processos de trabalho no PAAS agenciando-se aos interesses do território estudado e dos sujeitos participantes, dentre os quais destacamos neste artigo a experiência vivida com uma pessoa surdocega. Para lidar com as especificidades da surdocegueira busquei suporte em estudos filosóficos e sociológicos. Na filosofia, de grande ajuda foram as reflexões sobre a fenomenologia da percepção de Maurice Merleau-Ponty. Na sociologia, tornaramse muito operativos os conceitos de Pensamento Abissal e Ecologia de saberes trazidos por Boaventura de Souza Santos. Para uma reflexão filosófica sobre a arte, busquei em Rancière e sua política estética instrumentos para legitimar as experiências observadas. No campo da deficiência e da Surdocegueira, foram fundamentais os diálogos com os saberes de perspectivas biopsicossociais a respeito da surdocegueira. Os resultados apontam a relevância da arte para a expressão do ser, para a comunicação, para a ampliação da percepção e para o entendimento de mundo de pessoas surdocegas. Do mesmo modo, revelam o potencial do campo da surdocegueira para o campo das artes, suscitando ampliações e enriquecimentos nos modos de perceber, conceber, fazer e fruir arte.

Palavras-chave: Surdocegueira, Expressão Artística e Decolonialidade.

\section{Deafblindness, Cartography and Decoloniality}

\begin{abstract}
This article is composed of part of my $\mathrm{PhD}$ research, whose purpose was to search for interfaces between the Deafblind and Art fields. The work was developed with deafblind people, their relatives and professionals of the Program of Attention and Support to the Deafblind, from the Benjamin Constant Institute, located in Rio de Janeiro. Through the method of cartography, the research followed work processes in the Program of Attention and Support to the Deafblind taking care of the interests of the territory studied and the subjects involved, among which we highlight in this article the experience lived with a deafblind person. In order to deal with the specifics of deafblindness I sought support in philosophical and sociological studies. In the philosophy, of great help were the reflections on the phenomenology of the perception of Maurice Merleau-Ponty. In sociology, the concepts of Abyssal Thought and Ecology of knowledge brought by Boaventura de Souza Santos became very operative. For a philosophical reflection on art, I sought in Rancière and his aesthetic policy instruments to legitimize the observed experiences. In the field of disability and the Deafblindness, the dialogues with the knowledge of biopsychosocial perspectives on deafblindness were fundamental. The results point to the relevance of art to the expression of being, to communication, to the expansion of perception and to the world understanding of deafblind people. Likewise, they reveal the potential of the field of deafblindness to the field of the arts, raising extensions and enrichments in the ways of perceiving, conceiving, making and enjoying art.
\end{abstract}

Keywords: Deafblindness, Artistic Expression and Decoloniality. 


\title{
Sordoceguera, Cartografía y Decolonialidad
}

\begin{abstract}
Resumen: El presente artículo se compone de parte de mi investigación de doctorado, cuyo propósito fue buscar interfaces entre los campos de la Sordoceguera y del Arte. El trabajo fue desarrollado con personas sordociegas, sus familiares y profesionales del Programa de Atención y Apoyo al Sordociego (PAAS), del Instituto Benjamin Constant, situado en Río de Janeiro. A través del método de la cartografía, la investigación acompañó procesos de trabajo en el PAAS agenciándose a los intereses del territorio estudiado y de los sujetos participantes, entre los cuales destacamos en este artículo la experiencia vivida con una persona sordociega. Para tratar con las especificidades de la sordoceguera busqué soporte en estudios filosóficos y sociológicos. En la filosofía, de gran ayuda fueron las reflexiones sobre la fenomenología de la percepción de Maurice Merleau-Ponty. En la sociología, se tornaron muy operativos los conceptos de Pensamiento Abisal y Ecología de saberes traídos por Boaventura de Souza Santos. Para una reflexión filosófica sobre el arte, busqué en Rancière y su política estética instrumentos para legitimar las experiencias observadas. En el campo de la discapacidad y de la Sordoceguera, fueron fundamentales los diálogos con los saberes de perspectivas biopsicosociales acerca de la sordoceguera. Los resultados apuntan a la relevancia del arte para la expresión del ser, para la comunicación, para la ampliación de la percepción y para el entendimiento de mundo de personas sordociegas. De la misma manera, revelan el potencial del campo de la sordoceguera para el campo de las artes, suscitando ampliaciones y enriquecimientos en los modos de percibir, concebir, hacer y disfrutar arte.
\end{abstract}

Palabras clave: Sordoceguera, Expresión Artística y Decolonialidad.

\section{Introdução}

Meu encontro com o mundo da surdocegueira (SC) ocorreu em 2008 quando, virtualmente e pela primeira vez, vi o espetáculo "Not by bread alone", do grupo israelense de teatro Nalaga'at Theater. Os atores são surdocegos e o espetáculo, por onde passa, é aclamado. Quando vi o espetáculo fiquei confusa e com a percepção embaraçada. Tinha experiências de trabalhos artísticos, especificamente teatrais, com pessoas surdas, cegas, com baixa visão, com deficiência intelectual. Vivências artísticas desenvolvidas a partir dos diferentes modos de percepção e cognição dos participantes dos processos. Produtos artísticos criados para serem fruídos não apenas pela visualidade, nem somente pelas dimensões do som. Palavras, imagens, sons eram desafiados, transformados, traduzidos nas produções cênicas com as quais estive envolvida no início de minha formação. Criações artísticas no escuro, criações sem sonoridade, experimentos de diálogos e criações a partir de diferentes percepções sensoriais. $\mathrm{O}$ encontro virtual com o Nalaga'at ${ }^{1}$ Theater me desafiou a vivenciar e ampliar experiências artísticas no campo da SC. Devagar, adentrei outro mundo.
Pesquisando sobre SC percebi que há pouquíssimos trabalhos acadêmicos desenvolvidos na área da cultura e quase nada em relação à arte. Fora dos campos médico e educacional o desconhecimento é radical em relação à SC. Não encontrei referências de trabalhos desenvolvidos com pessoas surdocegas no campo das artes aqui no Brasil, apenas alguns pontuais experimentos que favorecem a acessibilidade cultural (Andrade, 2014). Além disso, ainda é bastante recorrente que os diversos campos do conhecimento abordem a temática da deficiência a partir de um prisma negativo, ou seja, entendendo-a apenas como falta e negação, numa perspectiva carregada de preconceitos. É comum acontecer a desvalorização das obras de artistas com deficiência ou das obras voltadas para pessoas com deficiência. Tudo isso ocorre com frequência, mesmo com o avanço das políticas públicas em prol dos direitos das pessoas com deficiência e dos esforços voltados para a ampla acessibilidade desta população.

Foi neste contexto que o presente trabalho se imbuiu da ideia de que a privação ou a diminuição dos sentidos audiovisuais em sujeitos com SC traz interferências nos modos de perceber, conhecer, entender,

${ }^{1}$ Nalaga'at, em hebraico, quer dizer: pode tocar. 
criar e fruir experiências artísticas. Este pensamento impulsionou-me a intensificar um estreitamento com o mundo da SC, o que causou a ampliação de meus conhecimentos sobre o assunto. Os esforços para a aquisição de conhecimentos sobre SC, ampliados e lastreados pela experiência, desvendaram um novo modo de ver esta realidade para além dos campos da saúde e da educação, detentores dos saberes mais significativos a respeito da SC, e em geral mais preocupados com as patologias, síndromes e seus efeitos no desenvolvimento da cognição, comunicação, reabilitação, mobilidade, sociabilidade etc., de pessoas surdocegas. O campo da criação e da experiência artística, aquele que mais me interessava, é infimamente explorado nos universos da SC, mesmo em nível internacional.

A pesquisa intencionava, ao penetrar no campo da SC, explorar o desenvolvimento de experiências artísticas cênicas junto a pessoas surdocegas no Programa de Atendimento e Apoio a Surdocegos (PAAS), do Instituto Benjamin Constant ${ }^{2}$ no Rio de Janeiro. Acompanhando processos de trabalho no PAAS, ao longo de todo o ano de 2014, a pesquisa agenciou-se aos interesses do território estudado, interveio nos mecanismos de atuação junto a pessoas surdocegas daquela instituição e evidenciou interfaces entre a SC, a arte e a expressão artística. No decorrer deste processo, no entanto, distanciou-se da linguagem cênica e estendeu suas intervenções ao campo das artes de um modo geral, dialogando com outras linguagens artísticas. A entrada como pesquisadora nesta instituição possibilitou encontros contínuos com pessoas surdocegas e a realização da pesquisa, mas, em contrapartida, dificultou o desenvolvimento das intenções iniciais de investigação pelos atravessamentos, burocracias e limites próprios de grandes espaços institucionais. Contribuíram para os reposicionamentos da pesquisa: o perfil cartográfico da minha atuação e intervenção no PAAS, as necessidades e emergências próprias do território estudado e os interesses dos sujeitos envolvidos com o trabalho. .

Uma das principais características da realização de uma pesquisa cartográfica é a dimensão do acompanhamento de processos. Como nos ensinam Passos, Kastrup e Escóssia (2010), cartografia em pesquisa é um método que não se faz por caminhos rigidamente preestabelecidos, mas traça suas rotas e metas no ato de caminhar, no decorrer dos percursos. O pesquisador não se propõe a estar num determinado campo apenas como observador distanciado dos processos que se desenrolam no ambiente da pesquisa. Ao contrário disso, insere-se/deixa-se inserir no campo que estuda. Sua proposição é esta e este é um dos objetivos que busca, ou seja, criar planos comuns de trabalho, de ação, de intervenção e de pesquisa. A pesquisa cartográfica afirma a importância do interesse daquele que investiga assim como também o interesse próprio do objeto. "O pesquisador sai da posição de quem julga a realidade do fenômeno estudado para aquela posição ou atitude de quem se interessa e cuida" (Passos, \&Kastrup, 2014, p. 29). A respeito da questão do encontro entre as intenções iniciais da cartografia e as realidades existentes, Alvarez e Passos apontam:

Na cartografia, o início da pesquisa é aparentemente mais organizado e sistemático. O projeto inicial é mais claro e com fundamentos precisos do que em seu desenvolvimento e conclusão. No entanto, essa organização inicial é forçada e dicotomizada, respondendo apenas aos anseios de uma ordem racional, abstrata e desencarnada. [...] No processo de se avizinhar e habitar o campo depara-se com um universo muito mais amplo e rico (Alvarez, \& Passos, 2010, p. 141).

Movida por estas características e princípios da pesquisa cartográfica, fui aos poucos adequando os interesses iniciais da pesquisa aos anseios e necessidades do campo.

Antes de seguir com a apresentação do caso que inspira este artigo, importa compartilhar algumas especificidades que caracterizam a dupla perda dos sentidos de distância e como a aquisição desta deficiência afeta o desenvolvimento integral dos sujeitos que a tem.

A SC se expressa pela incapacidade total ou parcial, porém simultânea, da audição e da visão. Desse modo, para determinar se alguém é ou se tornou surdocego ${ }^{3}$ é preciso que tal indivíduo não tenha visão suficiente para compensar a perda auditiva, ou o contrário, que não possua audição suficiente para compensar a falta de visão (Reyes, 2004). Vários aspectos definem a SC, mas um em especial podemos tomar como marca importante deste universo: a heterogeneidade presente nesta população. São diversas as possibilidades de dupla perda sensorial e cada uma vai imprimir um determinado tipo de vivência da SC na vida dos sujeitos que a tem ou adquirem. Alguns exemplos desta diversidade de possibilidades: o tipo e o grau da perda, o momento da aparição dos déficits 
sensoriais, a ordem em que aparecem, a etiologia, a existência ou não de outras deficiências associadas, o ambiente/contexto em que a pessoa vive etc.

Levando em consideração tais fatores, no que diz respeito aos diferentes níveis e tipos de SC há pessoas que nascem e outras que se tornam surdocegas e estes fatores imprimem diferenças cruciais na vida dos sujeitos (Cader-Nascimento, \& Costa, 2010; McInnes, 1999; Reyes, 2004). Segundo Cader-Nascimento e Costa (2010), em relação aos níveis, são possíveis as seguintes combinações: 1) Pessoas com cegueira e baixa audição; 2) Pessoas com surdez profunda e baixa visão; 3) Pessoas com baixa visão e audição; 4) Pessoas cegas e surdas profundas.

No que diz respeito aos tipos de SC, pode-se destacar: a congênita e a adquirida, ou a pré-linguística e a pós-linguística (Cader-Nascimento, \& Costa, 2010; Reyes, 2004). A primeira caracteriza-se pelo fato de a pessoa: 1) nascer surda e cega; 2) nascer surda ou cega e em pouco tempo adquirir a outra deficiência sensorial; 3) nascer ouvindo e vendo e depois adquirir as duas deficiências. O que caracteriza a SC congênita é a aquisição da dupla perda ou severa diminuição dos sentidos na fase pré-linguística. O segundo tipo caracteriza-se pelo nascimento de uma pessoa: 1) cega ou surda que adquire a outra deficiência na fase pós-linguística; 2) sem nenhuma deficiência e que adquire as duas deficiências após a aquisição de uma língua; 3) sem nenhuma deficiência, que adquire a surdez ou a cegueira na fase pré-linguística e na fase pós-linguística adquire a deficiência do outro sentido de distância. Importa esclarecer todos esses aspectos porque eles definirão modos e procedimentos diferenciados de desenvolvimento da percepção, da cognição, da comunicação, da sociabilização, da educação e da formação integral dos sujeitos surdocegos. Além disso, são aspectos fundamentais para a constituição de suas subjetividades. Assim, há uma grande variedade de pessoas abarcadas nesta ampla definição.

A combinação da perda dos sentidos de distância causa dificuldade no desenvolvimento interpessoal em dimensões comunicacionais, sociais, educacionais, culturais, afetivas, profissionais etc. Isso porque a relação de pessoas surdocegas com o mundo não se dá de forma direta, sendo quase sempre necessária uma mediação realizada por outra pessoa, vidente e ouvinte, que, preferencialmente, detenha conhecimentos e habilidades específicos que permitam a interferência na relação do sujeito surdocego com o mundo (Reyes, 2004).

As principais causas da SC congênita são: os nascimentos prematuros, a rubéola congênita, as meningites e síndromes diversas como CHARGE ${ }^{4}$, entre outras. Dentre as síndromes a da rubéola congênita é considerada a principal causa da SC congênita no mundo. A síndrome da rubéola congênita (SRC) decorre de uma complicação da infecção pelo vírus da rubéola durante a gestação, principalmente no primeiro trimestre, podendo comprometer o desenvolvimento do feto e causar aborto, morte fetal, natimorto e anomalias congênitas. Dentre as diferentes manifestações clínicas da SRC, destacam-se as de cunho permanente e as tardias. Estas causam: deficiência auditiva, malformações cardíacas, catarata, glaucoma, retinopatia pigmentar, retardo do desenvolvimento, diabetes mellitus. As crianças com SRC frequentemente apresentam mais de um sintoma, mas podem ter apenas uma malformação, dentre as quais a deficiência auditiva é a mais comum (Reyes, 2004).

Ainda de acordo com Reyes (2004), em relação à SC adquirida, as principais causas são: as síndromes de Usher e de Wolfram. Ambas são enfermidades de origem congênita com sintomatologias que só aparecem ao longo da vida das pessoas afetadas. Dentre as diversas síndromes a de Usher é considerada a principal causa de SC adquirida no mundo (McInnes; 1999). A Usher se transmite hereditariamente e caracteriza-se por surdez bilateral acompanhada de progressiva perda visual. Reyes aponta que há muitos tipos de síndrome de Usher, mas, atualmente, muitos teóricos da saúde classificam a síndrome a partir de três tipos principais onde a perda auditiva é a característica que as determina com as seguintes variáveis: tipo I surdez neurossensorial profunda e bilateral não progressiva e de nascimento. Associa-se à retinose pigmentar ${ }^{5}$, à alteração vestibular e à cegueira noturna já na infância ou adolescência; tipo II - surdez leve a moderada congênita, mas estável. No fim da adoles-

${ }^{4}$ CHARGE é uma sigla em inglês para a designação diagnóstica de um grupo de malformações congênitas que incluem várias anomalias. A síndrome de CHARGE é uma doença causada por uma mutação genética. Disponível em: http://www.eurordis.org/pt-pt/content/ sindrome-charge-batalhas-diarias-de-jonas 29

${ }^{5}$ A retinose pigmentar é “[...] um grupo de doenças degenerativas e hereditárias da retina. [...] A pessoa afetada apresenta diminuição da visão noturna, redução do campo visual periférico e, com o passar dos anos, podem ocorrer várias limitações visuais que não necessariamente a cegueira total" (Giacomini, Petersen, Cambruzzi, \& Maia, 2005, p. 16). 
cência ou na vida adulta da pessoa, às perdas auditivas estáveis associam-se as perdas visuais que são progressivas (em sua maioria decorrentes de retinose pigmentar) e chegam à cegueira; e tipo III - surdez neurossensorial congênita progressiva. Os déficits visuais somam-se aos auditivos ao longo da vida das pessoas, normalmente iniciam na puberdade ou adolescência. Os comprometimentos audiovisuais são progressivos, resultando na perda severa ou total da visão e audição na idade adulta ou meia idade (Reyes, 2004). Já a síndrome de Wolfram caracteriza-se por uma associação entre o diabetes e perdas auditivas e visuais, sendo estas provenientes do diabetes.

A aquisição de uma língua e/ou o desenvolvimento de uma linguagem comunicativa/expressiva por parte de pessoas SC também se dá numa grande variedade de caminhos, porque depende do tipo de possibilidade sensorial que o indivíduo dispôs até a chegada da dupla deficiência; da fase da vida em que adquiriu a SC; do domínio que tem da língua adquirida (oral ou Língua de sinais). Um exemplo: para uma pessoa que nasce surda e aprende a Língua de sinais, mas, quando chega à vida adulta, adquire também a cegueira, tornando-se surdocega, o modo de comunicação mais eficaz provavelmente será a Língua de sinais tátil, cuja aprendizagem será iniciada a partir dos conhecimentos da primeira língua. Se uma pessoa nasce surda ou ainda na infância perde a audição, mas é oralizada e se comunica por leitura labial, e, num determinado momento da vida também perde a visão, um meio de comunicação potencial é o tadoma que será introduzido com o amparo do meio de comunicação anterior (oralização e leitura labial) e da experiência visual da leitura labial. Portanto, há vários tipos de comunicação que podem ser utilizados com pessoas surdocegas e a escolha e uso deles depende de muitas variáveis. Dentre as possibilidades, e em consonância com Wanatabe, Giacomini e Maia (2006) e Watanabe e Maia (2012) destacam-se:

1. Língua de sinais tátil - a comunicação é feita através de uma adaptação da língua de sinais, cujos movimentos de mãos do intérprete comunicador são feitos de modo a serem tocados e por sua vez interpretados pelas mãos da pessoa com SC;

2. Braille tátil - quase sempre indicado para pessoas cegas que depois da aquisição de uma língua oral também adquirem a surdez. A comunicação se dá quando o intérprete comunicador, por meio de toques em determinadas falanges dos dedos da pessoa com SC faz correspondência com os pontos da cela Braille, e assim transmite a mensagem como se estivesse escrevendo em Braille;

3. Alfabeto datilológico ou alfabeto manual tátil - soletração de letras do alfabeto em língua de sinais;

4. Escrita do alfabeto/palavras de uma língua oral com um dos dedos da mão numa parte sensível do corpo de pessoas surdocegas (mãos, rosto, antebraço, coxa, costas). Geralmente a letra usada é a de imprensa;

5. Fala ampliada - feita ao pé do ouvido e num volume de som mais alto para surdocegos com cegueira e surdez moderada;

6. Língua de sinais aérea em campo reduzido - para pessoas SC com surdez profunda e baixa visão com perda de campo visual. Nesse contexto o comunicador precisa se encaixar no campo visual da PSC;

7. Escrita Ampliada - com aumento no tamanho das letras e no contraste, evidenciando a relação palavra/fundo, para surdocegos com baixa visão;

8. Tadoma - o SC coloca uma das mãos no rosto (maxilar, boca, bochecha) e pescoço do falante apoiando-a de forma que possa perceber, através da vibração das cordas vocais, do movimento do maxilar e da boca, bem como dos sopros produzidos, o que o falante está comunicando;

9. Placas alfabéticas com letras e números em relevo - estas têm cores contrastantes com o fundo para auxiliar pessoas com baixa visão. $\mathrm{O}$ uso das mesmas se dá quando a pessoa surdocega toca com o dedo a placa e percebe pelo tato cada uma das letras e números que formam a mensagem.

10. Placas alfabéticas em Braille - semelhante a anterior, sendo que as letras e números estão dispostos em Braille e assim a pessoa surdocega percebe a mensagem explorando pelo tato os pontos referentes a letras e números.

Conhecer bem a pessoa SC é a principal questão para desenvolver um trabalho com ela. É preciso ver que tipo de comunicação ela usa ou gosta de usar, ou a que tipo de comunicação melhor se adapta. O conhecimento de sua história e de seu desenvolvimento, além do estágio da perda, também é imprescindível para a realização de qualquer intervenção junto a estas pessoas. Segundo Cader-Nascimento e Costa (2010), são esses conhecimentos que definirão as prioridades que deverão constar nos planejamentos de trabalho e intervenção (elaborados e pensados especificamente para cada indivíduo) nas instâncias da comunicação, educação, sociabilização, reabili- 
tação, saúde etc. É imprescindível que se entenda o SC como um sujeito único e que se busque, com ele, os procedimentos e as estratégias necessários ao seu desenvolvimento integral. Apesar das grandes limitações, é possível desenvolver processos interventivos em diversos âmbitos levando pessoas com SC (congênita e adquirida) à conquista de uma vida sociabilizada e participativa na vida comum. A privação dos sentidos de distância (visão e audição) dificulta, mas, necessariamente, não impossibilita o desenvolvimento de indivíduos com SC (Cader-Nascimento, \& Costa, 2010; Reyes, 2004).

Tomando as especificidades da SC como esteio e orientação busquei dialogar com o campo a fim de encontrar aproximações entre este $\mathrm{a}$ as artes. O desenvolvimento do trabalho favoreceu o aparecimento de algumas experiências e dentre as vivências com as diferentes pessoas surdocegas com as quais convivi no decorrer desta pesquisa, escolhi compartilhar aqui o encontro com a Lia.

\section{Lia, a moça bordadeira}

Não me lembro quando percebi pela primeira vez ser diferente das outras pessoas, mas eu sabia disso antes da vinda de minha professora. Eu notara que mamãe e meus amigos não usavam sinais como eu quando queriam algo, mas falavam com a boca. Às vezes eu ficava entre duas pessoas que conversavam e tocava seus lábios. Como não conseguia entender, ficava perturbada. Movia os lábios e gesticulava freneticamente sem resultado (Keller, 2008, p. 9).

Estávamos em um grupo de 30 mulheres e, para finalizar a atividade, fizemos uma roda e brincamos de passar o anel. Ao passar o anel, mas ainda com mãos entre mãos, cada uma das mulheres deveria dizer para a companheira do lado algumas palavras que expressassem o significado daquela experiência. A roda foi girando e dentro dela estava Lia. Quando finalmente a palavra chegou à Lia, ela guardou o anel em suas mãos e repousou as suas mãos dentro das mãos da mulher ao seu lado. E olhando nos olhos da companheira Lia disse tudo que pode, balbuciando sons, murmúrios e sorrisos (Arheta - Trecho do relatório de campo da pesquisa).
Logo nos primeiros dias do trabalho de campo da pesquisa ora apresentada conheci a Lia, uma moça/ mulher que à época tinha 31 anos. Era uma moça muito doce e delicada, com semblante sereno e sempre feliz. Ela chegava ao PAAS acompanhada de sua mãe que a deixava na porta do setor e, depois, saía para caminhar um pouco pela Urca enquanto aguardava o atendimento. Lia se despedia da mãe com um beijo e se a mãe demorasse um pouco mais para sair ela repetia, tanto quanto fosse preciso, o movimento de tchau. A mãe então ia, Lia virava-se para a professora ou terapeuta ocupacional e abria um suave sorriso.

Lia é surdocega congênita, tem surdez profunda e baixa visão (proveniente de catarata) congênitas. Seu campo de visão central é um pouco comprometido, ela tem uma visão lateral melhor e uma razoável acuidade visual. Ela não se comunica através de uma língua estruturada, não foi alfabetizada em Libras ou na Língua portuguesa. Sua comunicação interpessoal se dá através de gestos.

A história da Lia foi contada a mim pela professora do PAAS e pela sua mãe. Da professora ouvi impressões sobre as possibilidades e limites relacionados à deficiência e sobre a condição funcional de Lia. Por não ter aprendido uma língua, Lia tinha um desenvolvimento cognitivo funcional, então ela repetia o que via: gestos, ações, movimentos. Copiava e reproduzia imagens, figuras, letras, palavras, mas isso não correspondia ao entendimento do significado da palavra, por exemplo. Na fala da professora:

A Lia, ela é uma delícia de se trabalhar. Todo mundo quer, todo mundo gosta, todo mundo quer alfabetizar a Lia... Eu desisti de lutar contra isso. Porque eu sei que é perda de tempo e é uma falta de respeito com a pobre da Lia. Porque Lia lê e Lia escreve, à maneira dela. Ela é uma pessoa que usa uma comunicação alternativa muito bem obrigada. $\mathrm{E}$ as pessoas acham que tem que alfabetizar, e tem que alfabetizar, e tem que alfabetizar. [...] O que ela reconhece é a figura e acabou. E é com a figura que ela fala. Ou com os gestos familiares e tudo. Então o trabalho com a Lia teria que ser esse mesmo, voltado para o lado artístico que ela tem, não tenha dúvida (Professora).

Agora, boa parte das ações que Lia repetia era entendida em suas intenções. Isso ficava claro quando conversava com sua mãe. 
Ela mesma me ensinou a me comunicar com ela. Quando ela queria alguma coisa ela pegava uma revista e já cortava e mostrava para a gente. Aí ela mostrava o quê que ela queria. Aí aprendeu a fazer xixi mostrando aqui (dirige a mão para o baixo-ventre)... Que ela queria comer, que ela queria beber água fazendo sinal de água em Libras. Ela mesma foi fazendo os sinais dela e a gente foi aprendendo. Se ela queria um absorvente ela ia lá e cortava. Se ela queria um biscoito ela ia lá e cortava no encarte (Hélia).

As experiências narradas pela professora e por Hélia com Lia e, posteriormente, as minhas próprias experiências com ela, punham-me em diálogo com as reflexões de Merleau-Ponty $(1980,1999)$ a respeito do fenômeno da percepção. A atenção do filósofo centrava-se no corpo, na percepção do corpo e das experiências corporais. Para Merleau-Ponty, é no corpo e pelo corpo que a vida e a compreensão da vida se manifestam, do corpo nasce o saber, o filósofo alça o conceito de consciência encarnada. Mas isso não significa reduzir o saber humano ao sentir. Sobre a questão, Masini (2012, pp. 21-22), precursora dos estudos sobre SC no Brasil, aponta:

A experiência perceptiva (que é corporal) surge da relação dinâmica do corpo com um sistema de forças no mundo e não da associação que vem dos órgãos dos sentidos. Assim, o corpo é visto numa totalidade, na sua estrutura de relação com as coisas ao seu redor - como fonte de sentidos. [...] Este filósofo, ao tomar a percepção como solo originário do conhecimento - percepção que se dá no corpo, nas relações de significação com o que se dá ao seu derredor - refere-se aos conteúdos particulares (a especificidade) e às formas de percepção (a generalidade). Os conteúdos são os dados sensoriais (visão, tato, audição) e a forma, a organização total desses dados, que é fornecida pela função simbólica. Há uma dialética entre conteúdo e forma: não se pode organizar nada se não houver dados, mas estes, quando fragmentados (dissociados da função simbólica) de nada adiantam. [...] Para compreender a pessoa e sua maneira de se rela- cionar no mundo que a cerca, há sempre que se considerar suas estruturas perceptual e cognitiva, que exprimem ao mesmo tempo generalidade e especificidade (o conteúdo, a forma e a dialética entre ambas). O ponto de partida é, pois, saber de sua experiência perceptiva.

As possibilidades perceptivas de Lia em diálogo com as experiências vivenciadas por ela na vida social, em sua comunidade, em sua família etc., favoreceram o nascimento e a construção de um conhecimento próprio do mundo. E para atuar junto à Lia, para estar com ela e com ela tentar criar um processo de trabalho artístico (que a essa altura da pesquisa eu já tinha entendido que não poderia circunscrever-se apenas à linguagem cênica) eu tinha que perceber e entender seus modos de perceber, compreender, ser e estar no mundo.

A SC de Lia era proveniente da rubéola congênita. Ela nasceu surda, com problemas no coração e no primeiro ano de vida desenvolveu catarata o que a deixou com baixa visão. Ela tem perda de visão central, cujos efeitos são semelhantes ao representado na Figura 1. Lia é surdocega pré-linguística, não foi alfabetizada em nenhuma língua e sua comunicação se dá através da utilização de gestos. Uma tecnologia assistiva bastante eficaz para ela seria as placas de comunicação ${ }^{6}$.

Inicialmente observei bastante a Lia, o que fazia no setor (atividades orientadas e espontâneas) e foi

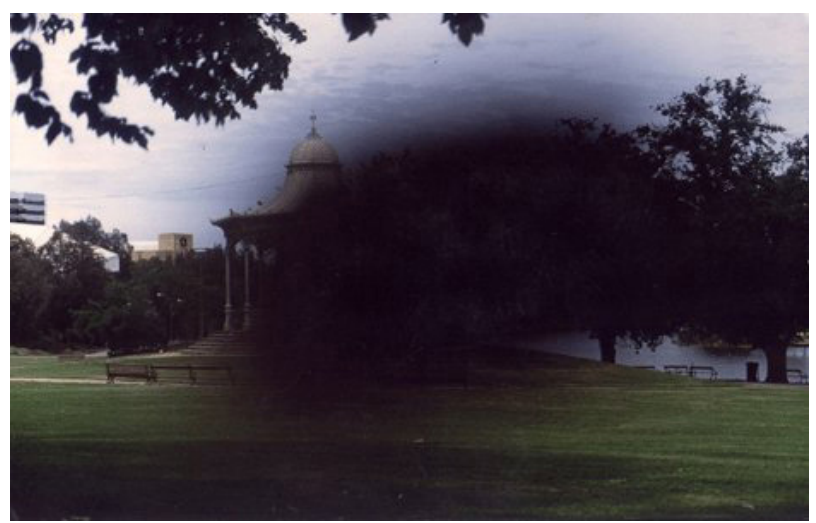

Fonte: http://www.mdsaude.com/2009/08/degeneracaomacular.html. Acessado em março de 2016.

Figura 1

Foto de imagem que simula a perda de visão central.

${ }^{6}$ Placas ou pranchas de comunicação são estratégias de comunicação alternativa para pessoas sem fala ou sem escrita funcional ou em defasagem entre sua necessidade comunicativa e sua habilidade de falar e/ou escrever. Disponível em: http://www.assistiva.com.br/ ca.html. Acessado em março de 2016. 
nestas observações que encontrei caminhos de atuação junto a ela. Lia chegava ao PAAS disposta e aberta a qualquer atividade, mas sempre que sobrava um tempo ela se dirigia a um armário do PAAS e pegava uma caixinha com lãs, linhas e agulhas, as quais tentava entrelaçar. Fazia isso rápido, para aproveitar o resto de tempo que sobrava. Sentava novamente no salão e muito concentrada, punha a caixinha no colo, escolhia uma linha, a envolvia no pescoço, empunhava uma agulha de crochê e trançava suas linhas. Vi a Lia fazendo isso com linhas, lãs e até usando um carretel de barbante. Ela não ia avante na trama produzindo uma peça até o final. Sempre fazia, desmanchava, fazia de novo... e assim ia. Sempre que podia, que sobrava tempo, ela ia até o armário, pegava a caixinha e punha-se a trabalhar com as linhas. Essa era a linguagem artística de Lia. Mas não dei, de imediato, importância a seu interesse. Ela precisou repeti-lo algumas vezes para que eu me desse conta de que o meu caminho com ela poderia ser aquele. Isto aconteceu porque o primeiro semestre de 2014 na companhia das pessoas do PAAS foi muito intenso. Várias coisas aconteceram ao mesmo tempo. Múltiplas situações e ações, muitas diferenças para perceber e assimilar. Os dias de Lia no setor coincidiam com os de outras pessoas surdocegas que eu também observei inicialmente e com as quais busquei posteriormente caminhos. Então eu exercia uma atenção plural e singular. Esse perfil de atuação em diálogo com o campo fez com que eu me deparasse com o traço artístico da Lia muitas vezes até que finalmente entendesse que o caminho era aquele. Assim, fiquei um longo período pela tangente da Lia, observando, percebendo, entendendo, afetando-me, tornando-me parte.

$\mathrm{Vi}$ a cena relatada acima algumas vezes. Via sem ver. Eu ainda estava muito impregnada de um conceito de arte preestabelecido. E não queria estar. De repente me vi às voltas com mil dúvidas, dizendo para mim mesma: "Não posso bordar barras de panos de prato com a Lia!” Por que fui tomada por isso? Sempre trabalhei com culturas populares, com arte popular. O que estava acontecendo? Eu atravessava o campo e ele também me atravessava. O que é Arte? Conceitos, hierarquias, relações de poder... não queria pensar assim. Expressão artística, expressão cultural, expres- são poética é arte, cultura, poesia... É poiesis. Pensamentos, práticas, fazeres decoloniais (Santos, 2002; 2007). Era com eles que buscava tecer a pesquisa.

Santos, apresenta-nos os conceitos de Pensamento abissal e de Ecologia de saberes. O primeiro é uma forma de pensamento que se estrutura num sistema de distinções visíveis e invisíveis, a última fundamentando a primeira. Distinções invisíveis são estabelecidas por linhas radicais que dividem a realidade social em dois universos distintos: o universo "deste lado da linha" e o universo do "outro lado da linha". A divisão invisibiliza o outro lado da linha tornando-o inexistente. Assim, a característica basilar do pensamento abissal é a impossibilidade de coexistência/ copresença dos dois lados da linha. "Para além 'deste lado da linha' há apenas inexistência, invisibilidade e ausência não dialética" (2007, p. 2). Para Santos, o pensamento moderno é um pensamento abissal e o conhecimento e o direito modernos são as manifestações que melhor representam tal pensamento. $\mathrm{O}$ argumento central de Santos é que o pensamento moderno ocidental opera mediante linhas abissais que dividem o mundo humano do subumano, de modo semelhante ao pensamento que constituía o período colonial'. Hoje, como no período colonial, a criação e ao mesmo tempo a negação do outro lado da linha fazem parte integrante de princípios e práticas hegemônicos que se valem de pensamentos e práticas de apropriação e violência aplicadas do lado da linha tornado invisível ${ }^{8}$.

O conceito de Ecologia de Saberes, nasce da análise que este sociólogo faz a respeito do pensamento moderno e suas implicações sociais. Ecologia de Saberes consiste no reconhecimento de uma pluralidade de formas de conhecimento além do conhecimento científico presente no mundo. À questão da pluralidade de saberes somam-se as relações de poder e subalternização que algumas formas de saber impõem a outras, inclusive com a finalidade de invisibilizá-las. O conceito de Ecologia de saberes cunhado por Santos intenta apagar as linhas abissais que separam e invisibilizam diferentes saberes, formas de existência, culturas, conhecimentos etc. O que constitui a ideia de Ecologia de saberes é o fato de que nos diferentes saberes não se pode determinar sua validade em termos gerais e abstratos. Os saberes valem de

\footnotetext{
${ }^{7}$ Para Santos as colônias representam um modelo de exclusão radical ainda hoje presente no pensamento e práticas modernas ocidentais. 8 "A apropriação e a violência tomam diferentes formas na linha abissal jurídica e na linha abissal epistemológica. Mas, em geral, a apropriação envolve incorporação, cooptação e assimilação, enquanto a violência implica destruição física, material, cultural e humana" (Santos, 2007, p. 7-8).
} 
acordo com a pragmática da vida, com as consequências. Esta ideia defende que a compreensão do mundo é muito mais ampla que a compreensão ocidental do mundo. As formas de entendimento de mundo, de existência, de ser e estar no mundo são diversas e infinitas e não há nenhuma teoria que possa abraçar toda essa experiência. Então se a compreensão do mundo é muito mais ampla, temos que entrar com outros conhecimentos e esses conhecimentos vão nos dar uma ideia. A essa ideia Santos chama de Ecologia dos saberes. E os diferentes saberes significam também que não há apenas uma forma de ignorância, há várias ignorâncias (Santos, 2002; 2007).

Que desafio exercitar a autocrítica neste percurso. Respirei fundo, numa determinada manhã decidi passear, mais uma vez, pela ala da reabilitação do Instituto Benjamin Constant (IBC). Quando entramos no IBC, logo após a portaria temos que decidir entre três caminhos, isso no andar térreo. Seguir em frente, onde adentraremos o Instituto, dobrar à direita onde encontraremos uma ala médica, ou dobrar à esquerda e dirigirmo-nos à ala dos atendimentos e oficinas de reabilitação. A reabilitação do instituto:

[...] atende pessoas com deficiência visual adquirida na idade adulta (reabilitandos) proporcionando-lhes um elenco variado de atividades: orientação e mobilidade, atividade da vida diária, habilidades básicas de preparação para o Braille, leitura e escrita através do Sistema Braille, escrita cursiva, inglês básico, música, teatro, cestaria, artesanato (biscuit, tricô, tapeçaria) cerâmica, educação física, capacitação de usuários de computadores equipados com software do sistema dosvox, do magic (ampliador de tela para pessoas com baixa visão) e do jaws (leitor de tela), atendimento social e psicológico. Oferece também cursos profissionalizantes: massoterapia, shiatsuterapia, drenagem linfática manual, reflexologia dos pés, afinação de piano, oficina de cerâmica. A reabilitação desenvolve ainda o Programa de Atendimento e Apoio ao Surdocego e o encaminhamento ao mercado de trabalho de alunos e reabilitandos (site IBC $^{9}$ ).

De todas as oficinas e cursos oferecidos, peneirando para ressaltar as que dialogam com o campo das artes, temos: música, teatro, cestaria, artesanato (biscuit, tricô, tapeçaria) cerâmica e afinação de piano. As oficinas de música (violão e canto coral), cerâmica e artesanato são ministradas por profissionais com formação nas áreas de música e artes visuais, concursados para a prestação deste serviço. As de cestaria, biscuit, tricô e tapeçaria, por profissionais da casa que criaram estas oficinas, mas que não necessariamente entraram na instituição para realizar esta atividade. $\mathrm{E}$ a oficina de teatro é oferecida quando aparece algum voluntário, o que, na prática, pode ser qualificado ou não para a tarefa. Passei muito superficialmente por essas oficinas, mas entrei em contato com os resultados delas por um trabalho ou outro feito pelos reabilitandos do PAAS. Eram cestinhas feitas de folhas de revista, carteiras feitas de caixas de leite, flores feitas de material reciclável, e uma série de outros objetos. Alguns eram muito bonitos, e muitos reabilitandos adoravam essas atividades. No entanto, elas me faziam pensar nas relações entre arte e artesanato, traziam à tona a velha discussão: artesanato é arte? Uma seara na qual não queria entrar. O que importava de todo esse pensamento era: preciso ver o que os sujeitos criam. Não uma técnica que reproduzem. A questão do artesanato é muito forte no Instituto. Mas as oficinas de cerâmica e de música conseguem extravasar a criação, apesar das amarras impostas pela religião evangélica que também compõe os perfis religiosos e culturais de boa parte dos reabilitandos.

Antes de eu intervir com uma ação, essa possibilidade/caminho da Lia interveio em minhas questões de pesquisadora. Lia tramava linhas em restos de pano, numa beirinha de pano de prato, talvez até tivesse trançado linhas numa toalha. São especulações. Mas a percepção do gosto da Lia pelo trabalho com agulhas e linhas me colocava diante de alguns dilemas. $\mathrm{O}$ fato era que Lia gostava do trabalho com agulhas e linhas, mas ela não sabia como fazer e se eu quisesse adentrar este mundo com ela teria que ensinar como se faz. Acontece que esta ideia de trabalho me enchia de dúvidas e reservas. Por quê? Colocava-me diante do receio de encontrar apenas a técnica quando procurava a criação. Mas Lia aparentava gostar deste tipo de trabalho, apesar de não saber fazê-lo, ela teria, talvez, que aprender comigo. Mas como se eu também não sabia? Além disso, eu não desejava e até achava que não podia começar bordando panos de prato. E questionava-me sobre os porquês de pensar assim. Abaixo compartilho um trecho de meu diário de campo, escrito em abril de 2014:

${ }^{9}$ http:/ / www.ibc.gov.br/?catid=107\&blogid=1\&itemid=384 
Estou fazendo uma pesquisa de doutorado. Sou uma professora de arte. Como posso apresentar um resultado de pesquisa relacionado a bordados em panos de prato? Como eu, professora de arte, posso dialogar com uma técnica de reprodução? Estou sendo preconceituosa!? Não quero reproduzir uma técnica. Já sei! Não preciso bordar panos de prato, posso fazer um cachecol com ela, um xale... Não. Dáno mesmo.É reprodução de técnica. Depende...

Muitos juízos de valor ocuparam minhas reflexões. Por que eu não poderia colocar esse saber do bordar panos de prato na pesquisa? Não estaria sendo preconceituosa? Não estaria fazendo juízo de valor sobre os diferentes saberes? Não estaria presa a um conceito de arte que hierarquizava modos/fazeres/saberes/? Esse era um saber/fazer que interessava a Lia. O desejo por aprender aquele saber/fazer do bordar poderia me levar a uma de suas expressões artísticas. Ele aparecia insistentemente, nas bordas das suas ações, no resto de tempo que sobrava, nas poucas condições materiais que tinha (duas agulhas - uma de tricô e outra de crochê e algumas linhas com poucas cores). Outra característica do trabalho com ela era que a relação com a Lia tinha que se passar pelo fazer. Ela não se comunicava através de uma língua. Então para aprender com ela precisava estar com ela numa situação prática.

Lembrei-me de John Dewey. Fazia tempo que não me enredava em seus livros. Foi quando, mais uma vez, busquei sua companhia:

Para compreender o significado dos produtos artísticos, temos que esquecê-los por algum tempo, virar-lhes as costas e recorrer às forças e condições comuns da experiência que não costumamos considerar estéticas. Temos de chegar à teoria da arte por meio de um desvio. [...] Para compreender o estético em suas formas supremas e aprovadas, é preciso começar por ele em sua forma bruta; nos acontecimentos e cenas que prendem o olhar e o ouvido atentos do homem, despertando seu interesse e lhe proporcionando prazer ao olhar e ouvir (Dewey, 2010, pp. 60-61).

Meu reencontro com Dewey fez-me lembrar de minhas origens. Sou pernambucana, nasci na terra da renda, da renascença. Tenho algumas roupas bordadas e rendadas, eu gosto. Rendas de bilro, de renascença, de crochê, em filé. Bordados à mão, em richelieu, em labirinto, em matiz, em ponto de cruz. Realmente, gosto de rendas e bordados. Às vezes, me visto com roupas bordadas ou rendadas. Refiz minha atenção e estratégias e procurei me recolocar diante da Lia.

Quando Lia chegava ao PAAS ela abraçava as profissionais. Sempre abraçava todos que a cumprimentava. Era o jeito de falar com ela, de, inicialmente, se comunicar. Então quando ela chegava e uma profissional da casa se levantava para recebê-la e cumprimentá-la, eu me levantava também e punha-me ao lado para que Lia me visse. Ela passou a me ver e eu passei a ser abraçada por ela também. Mas esse exercício tão necessário e importante na área da SC, entrar no campo visual do outro, me fazia refletir sobre como eu queria entrar no campo visual da Lia. Era curioso esse exercício, para mim duplo, porque não queria apenas entrar em seu campo visual, mas também em seu mundo. Mas como entrar no mundo de Lia? Ou melhor, num pedaço de seu mundo? Um dia, fui com um vestido bordado em matiz para o PAAS. A intérprete foi recebê-la na porta de entrada e eu fui junto. Eu fui bordada para Lia me ver. Foi quando passei a existir. Num trecho do diário de campo...

Lia entrou na casa do PAAS e abraçou a intérprete que foi recebê-la. Eu seria a próxima, estava atrás daquela profissional. Quando chegou minha vez Lia não me abraçou, aproximou-se, olhou o colo do meu peito, levantou a mão e, com o dedo indicador tocando na pala do meu vestido bordado em flor, alisou cada uma das pétalas das flores, com calma, atenção e encantamento. Depois olhou para mim e me deu um abraço.

Foi assim que, em maio de 2014, ainda acompanhada de algumas dúvidas decidi iniciar uma intervenção com a Lia. Não sabia bordar, mas já tinha arriscado, algumas vezes, tramar linhas. Pensei bastante se iniciava fazendo crochê em paninhos, ou se trabalhava com a Lia em cima de alguma peça de tricô. Foi quando numa de minhas idas e vindas ao Instituto de Arte $\operatorname{Tear}^{10}$ (a partir deste mês de maio iniciei um processo de compartilhamento de conhe-

${ }^{10} \mathrm{O}$ Tear é um Instituto de Arte e uma organização não governamental (ONG). Atua nas áreas da arte, educação, arte-educação, educação ambiental, cultura, produção cultural e mobilização social. Fica situado na Tijuca/RJ e seu público alvo é crianças, adolescentes e jovens para cursos de arte nas diferentes linguagens, e também o público adulto para formação nos campos da arte e da educação. 
cimentos na área da Acessibilidade Cultural com a equipe do Instituto ${ }^{11}$ ) soube de um curso de bordado que seria realizado pelas Irmãs Dumont ${ }^{12}$, no mês de agosto e lá no Tear.

Conhecia o trabalho das Irmãs Dumont. Conheci através do Tear que tinha parceria artística com elas e com a ONG que administram ${ }^{13}$. A parceria existia não porque no Tear fosse oferecido curso de bordado, tecelagem ou coisa parecida. Mas pelo trabalho com a cultura popular brasileira, aspectos comuns ao Tear e à ONG das Irmãs Dumont. Pensei que participar do curso de bordado livre das Irmãs Dumont com a Lia seria ótimo. Busquei articulações com o Tear, com as Irmãs bordadeiras, com a professora do PAAS e com a mãe da Lia.

A parceria institucional entre o Tear e as Dumont proporcionava, dentre outros aspectos, ao primeiro: duas vagas no curso (que era pago); às segundas: o espaço para a realização da atividade porque as Irmãs são de Pirapora/Minas Gerais. Entrei nesta parceria solicitando ao Tear preencher essas duas vagas com a Lia e sua mãe e em troca eu ajudaria a ciceronear as Irmãs na produção/organização do que precisassem durante o andamento do curso. Eu era da casa, uma das profissionais do Tear, e sabia da constante colaboração que toda ONG necessita. Além disso, a presença da Lia no Tear instigaria o desejo do Instituto de atuar com pessoas com deficiência e enriqueceria nossas experiências de ampliação das ações de acessibilidade cultural. Parceria feita e muitos desafios a enfrentar. As oportunidades apareceram, juntei os fios de diferentes histórias para tecer algumas tramas e quando o fiz precisei assumir muitas responsabilidades. Pulverizei minha atenção, ação e dedicação. Estive no curso das Dumont como produtora, auxiliar, pesquisadora, intérprete, instrutora mediadora e aluna (afinal, tinha que aprender para ensinar, porque depois do breve curso das Dumont almejava continuar bordando com a Lia). Tramava todos esses fios em busca da abertura de percepções, caminhos, possibilidades.

A parceria com a professora e demais profissionais do PAAS foi viabilizada pela abertura da equipe à minha pessoa e às minhas propostas. Tudo que eu percebia e que em mim suscitava ideias eu ia compartilhando com as profissionais. Fomos caminhando juntas, elas dando abertura para minha intensa observação e constante presença no setor e depois para minhas intervenções. A ideia da participação no curso de bordado foi muito bem recebida.

Com a mãe a parceria aconteceu por via do afeto. Trocávamos conversas, impressões sobre a Lia e eu procurava recebê-la afetuosamente. Havia uma prática no PAAS de minimizar a entrada dos familiares no setor. As justificativas dadas para tal postura eram muitas, eu as compreendia, com algumas concordava, com outras não, mas evitava expor minhas opiniões a respeito, porque tinha a impressão de que não seriam ouvidas e não estava lá para convencer as pessoas. $\mathrm{O}$ fato era que na pesquisa que desenvolvia eu precisava estreitar laços com as pessoas que tinham suas vidas atravessadas pela SC, e isso incluía os familiares. Como fazer isso naquele território que trabalhava para cercear o que julgava como "excessiva aproximação dos parentes"? Eu não podia tentar pesquisar com pessoas surdocegas apenas ouvindo os relatos de profissionais sobre elas. Desde o início do campo explicava que iria pesquisar com as pessoas, mas isso só foi sendo entendido na prática. Com minhas ações, desde o início eu me posicionava. Não coloquei em discussão a questão, apenas agia me aproximando dos familiares e ponto. Se era dentro ou fora do PAAS não importava. Se naquele território tinha pouca abertura para fazer aproximações dentro da casa, então evitava. Foi assim que fui conversando com a mãe da Lia, do lado de fora da casa, num trecho de sua caminhada na Urca, na fila de espera do refeitório ou da cantina do IBC, num banco da Praça dos Ledores (uma pracinha que fica dentro do IBC) etc. Estreitamos laços nas bordas da casa do PAAS. Assim, a mãe topou participar do curso de bordado com a Lia lá no Tear.

Um pouco antes do curso com as irmãs Dumont decidi iniciar alguns experimentos com agulhas e linhas com a Lia, para ver como ela e eu nos sairíamos.

\footnotetext{
${ }^{11}$ No mês anterior eu tinha terminado um curso de especialização em Acessibilidade Cultural oferecido pelo Departamento de Terapia Ocupacional da Universidade Federal do Rio de Janeiro (UFRJ). Neste curso estava como representante do Tear, onde trabalhava. O trabalho de conclusão de curso (TCC) entrelaçou os campos da Surdocegueira e da Acessibilidade Cultural. O título é: "Acessibilidade Cultural e Surdocegueira: Desafios e Proposições".

${ }^{12} \mathrm{O}$ grupo das irmãs Dumont, chamado Matizes Dumont, é formado por seis artistas de uma mesma família de Pirapora, Minas Gerais. O grupo dedica-se: às artes plásticas e a desenvolver imagens bordadas que se transformam em ilustrações de livro, CDs etc.; à arte-educação; a projetos de mobilização social por meio da arte. Com seus bordados e poemas escreveram e ilustraram alguns livros como os dos escritores Manoel de Barros e Marina Colasanti e CDs de artistas como Maria Bethânia. Disponível em: http://www.icadbrasil. org/\#!matizes-dumont/cp7k. Acessado em junho de 2015

${ }^{13}$ Instituto de Promoção Cultural Antonia Diniz Dumont (ICAD), em Pirapora, MG.
} 
Comprei linhas de cores diversas, um corte de tecido bom para bordar, bastidores e agulhas para $\operatorname{cegos}^{15}$. $\mathrm{O}$ primeiro dia foi engraçado porque me aparamentei toda de materiais para bordar (panos, linhas, agulhas) e de registro (filmadora, câmera, tripé) e... nada. Lia não pôde ir ao encontro neste dia. Ela morava na Vila do João, no Complexo do Alemão, e nesse período sua comunidade estava em intensos conflitos com as Unidades de Polícia Pacificadora (UPPs) da região que reprimiam o tráfico, provocando transtornos e impedimentos à população. Na semana seguinte já fui menos aparamentada de material de registro. Levei parafernália de registro apenas uma vez para o instituto e de algum modo senti que ela evidenciava muito uma posição de observadora, da qual cada vez mais queria me afastar. Na segunda tentativa de encontro Lia foi e eu tinha, à tira colo, apenas o material para bordar. Cortei o pano na forma de um quadrado, risquei uma grande margarida e começamos. Lia adorou e muito rapidamente aprendeu os primeiros pontos e nós. A partir de então fui bordando com ela os nossos caminhos.

Participar do curso, que durou uma semana com aulas diárias, foi uma experiência muito interessante para nós (eu, Lia e sua mãe), para as irmãs Dumont e também para as outras mulheres que participaram como alunas (em sua maioria senhoras de classe social média e alta). Dentre as pessoas participantes, apenas a Lia e sua mãe eram moradoras de comunidade de baixa renda. Mas lá, no corpo a corpo da aula, esse fator fez nenhuma diferença. Ressoava o nosso comum, ali partilhado (Rancière, 2005a e 2005b), éramos todas mulheres com o interesse comum de bordar nossas histórias. Foram encontros delicados, bonitos e muito poéticos. Os ensinamentos do bordado eram feitos de modo a resgatar poeticamente as histórias pessoais de cada uma das mulheres.

Cuidei do ambiente onde a aula aconteceu para que tivesse luz, o salão destinado à oficina era mal iluminado. Esse fator foi agravado pelo fato de o curso se estender até o início da noite e também da luz do dia estar mais amena pelo tempo chuvoso e nublado. Então coloquei dois grandes refletores de luz no salão e sentava-me com a Lia embaixo de um deles. Atuei como instrutora mediadora da Lia. A Sávia, professora bordadeira, me explicava os pontos e eu explicava para Lia. Além disso, apresentava à Lia tudo o que a professora Sávia ia compartilhando com as outras alunas, apro- ximava os bordados trazidos pelas irmãs para ela ver etc. E nas atividades lúdicas procurava estar por perto. Quando eu não estava, a mãe da Lia a auxiliava. Uma coisa boa aconteceu com a mãe da Lia durante esses dias que passamos juntas. Ela foi entrando no mundo do bordado, foi se deixando levar pelo curso e dinâmicas e até esqueceu um pouco da filha. Num dos dias teve um momento da aula que precisei me retirar do salão principal para procurar um material em outro ambiente. Demorei uns 20 minutos para voltar e quando voltei encontrei Hélia bordando na copa do casarão e Lia no salão bordando junto com outra mulher.

A presença da Lia no grupo foi bem marcante. Todas as mulheres presentes foram bastante acolhedoras, mas nenhuma tinha vivido a experiência de estar na companhia de uma pessoa surdocega. As próprias irmãs Dumont ficaram temerosas quanto às suas capacidades para acolher uma pessoa com deficiência e certificaram-se de minha presença em todos os dias do curso. No final, agradeceram nossa participação. A Hélia e a Lia se deliciaram com a experiência. Iniciaram seus bordados e através deles me falaram um pouco de suas histórias.

Foi muito bonito ver a Lia acompanhar, no tempo dela, todas as orientações que eram dadas pela Sávia e mediadas por mim e também pela Hélia. Sua riqueza de entendimento do mundo, pelo olhar atento, apesar da baixa visão, chega a impressionar. Ela percebia e correspondia às dinâmicas corporais, cantadas, faladas do jeito dela e também prestava muita atenção, compreendia e reproduzia as técnicas de bordado ensinadas pela Sávia e mediadas por mim ou por Hélia. E depois de a Ana exercitar um ponto e outro, ela se arriscava a inventar. Porque ali havia o espaço da técnica, da fruição de muitas obras e imagens de obras bordadas que foram levadas pelas irmãs. Mas ali, naquela roda de mulheres havia, principalmente, espaço para criar.

Alguns modelos de desenhos, matrizes para posterior bordado em cima, foram ofertados pelas irmãs que os trouxeram na bagagem, outros eram feitos/criados por nós e isso também foi bastante incentivado. Assim, no desenho base e no pano base para o bordado da Lia, demonstrados nas figuras 2 e 3, entraram modelos oferecidos pelas irmãs e também desenhos livres feitos por ela a partir de seu imaginário.

\footnotetext{
${ }^{15}$ Esta agulha tem o fundo em $\mathrm{V}$ para a pessoa cega pressionar a linha na ponta da agulha e encaixá-la ao invés de enfiá-la no buraco.
} 


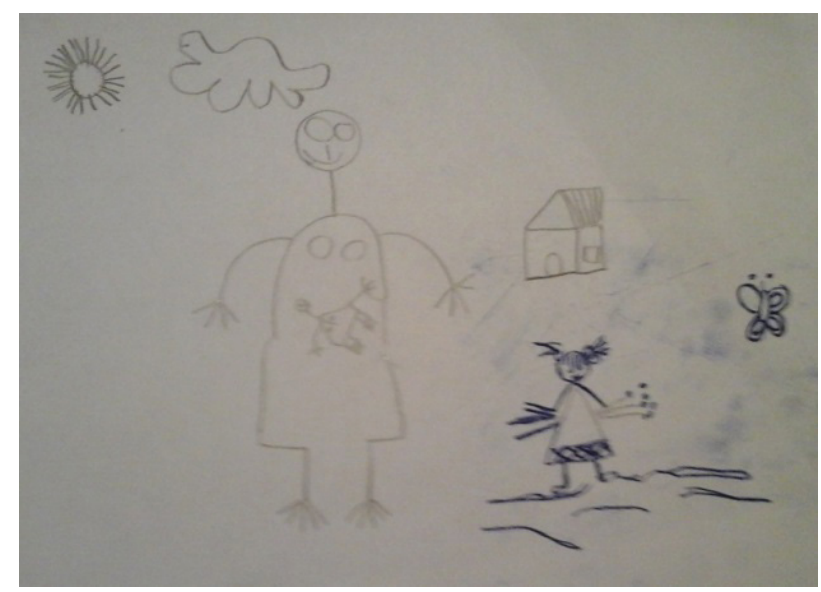

Figura 2

Foto do desenho base criado por Lia.

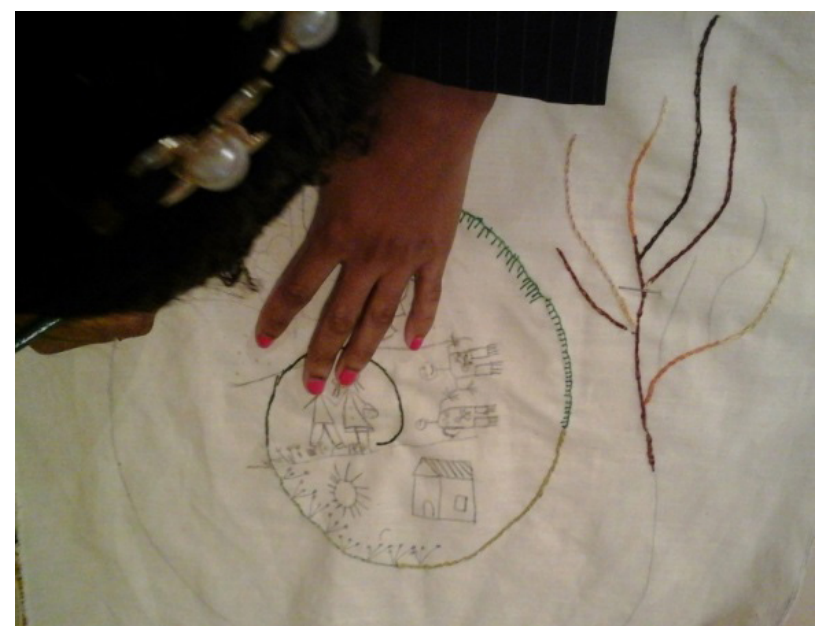

Figura 3

Foto de Lia desenhando imagens em seu pano base para o bordado.

Um dos momentos mais comoventes (no sentido de co-mover) do curso aconteceu no último dos cinco dias de encontro. Ele está descrito na epígrafe deste caso. Brincamos de passar o anel ${ }^{16}$ uma para a outra, com o foco no relato de como foi aquela experiência para cada uma. O jeito de brincar foi adaptado, naquela roda de mulheres bordadeiras era só passar o anel para a pessoa do lado e falar. Era a palavra que estava em jogo. Lia estava na roda. A Hélia também estava na roda, muita calma, esperando. Eu estava fora filmando. A palavra foi rodando, rodando, as mulheres desfiaram desejos e gratidões. A palavra se aproximava... o que ia acontecer? Chegou a Hélia que, da companheira do lado, recebeu palavras de admiração. Da Hélia foi para Lia palavras banhadas de bênçãos. E da Lia foi para a senhorinha do lado um balbuciar de sons e murmúrios que retornaram para Lia, traduzidos em carinhos feitos em suas mãos.

Algumas situações vivenciadas durante o curso me incitaram a refletir sobre questões político-culturais. A atividade acima foi uma delas. Evidente que havia uma lógica ouvintista e visuocêntrica imperando ali. Eu não podia retirá-la, não conseguiria. Não porque estava apenas como pesquisadora e isso seria uma tarefa hercúlea e tal. Mas porque a maioria dos participantes do curso era ouvinte e vidente e toda insana tentativa de negação da audição e visão poderia resultar em fracasso. Lia é surda congênita, não fala e tem baixa visão, mas, apesar da baixa visão, tem uma cultura visual. Mas eu não estaria impondo uma lógica ouvintista para Lia? Talvez... ali, no calor daquela experiência, buscava desestabilizar lógicas hegemônicas e nos cercava, tanto quanto podia e tinha condições, de estratégias de acessibilidade (atitudinal, estética, física e comunicacional). A SC nos coloca diante de muitos desafios. Tudo que eu tinha experimentado, estudado, lido, vivenciado, pesquisado sobre deficiência nos âmbitos políticos, culturais, sociais e biológicos ao longo dos últimos 10 anos era nas experiências colocado em xeque. Muitas coisas a se descobrir, experimentar, vivenciar, pesquisar junto às pessoas que convivem com a SC, ainda mais assim, abordando-a em perspectivas políticas, socioculturais e poéticas.

Terminamos o curso das Irmãs e combinei com Hélia que daríamos continuidade aos bordados no PAAS. Mas não conseguimos realizar este intento. Nas duas semanas posteriores ao curso tentamos sentar para bordar, no entanto, o ambiente e as condições não eram favoráveis. Não senti abertura para continuar o bordado com a Lia e a Hélia dentro da casa. Mas também não podia fazê-lo fora, porque assim eu iria dar continuidade com cada uma separadamente. Tentei contornar essa dificuldade, mas não consegui. Então continuei a bordar no setor apenas com a Lia, como se vê na figura 4. Apesar das tentativas para dar continuidade ao trabalho, o nosso bordado ficou inacabado, como mostra a figura 5.

\footnotetext{
${ }^{16}$ Uma brincadeira popular que consiste em esconder um anel, que está nas mãos de um jogador, nas mãos de outro jogador. O jogador que passa o anel faz suas mãos circularem nas mãos dos brincantes que estão dispostos numa roda. Enquanto a mão com o anel passa de mão em mão, os brincantes cantam uma música. Nesse intervalo o anel é deixado nas mãos de um dos participantes. Quando a música termina outro participante é escolhido para adivinhar com quem o anel ficou.
} 


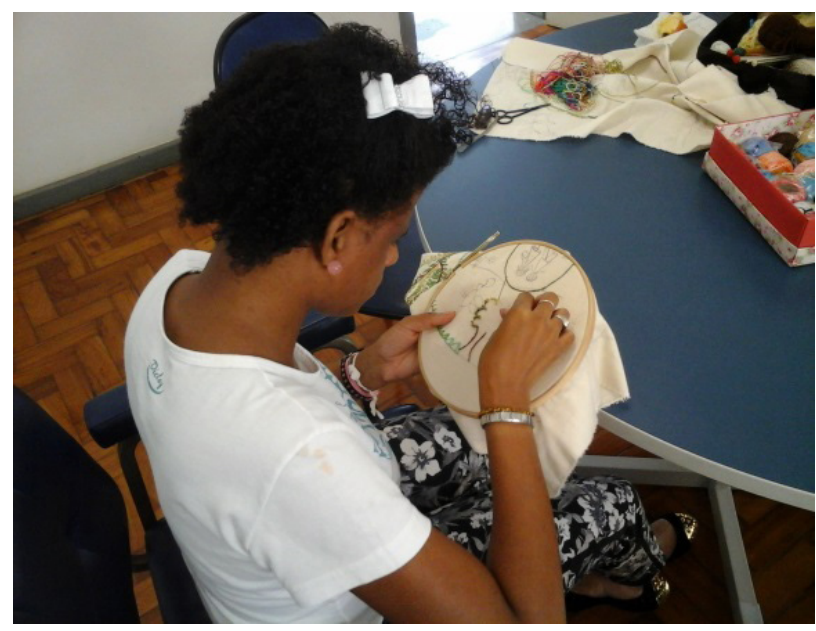

Figura 4

Lia bordando.

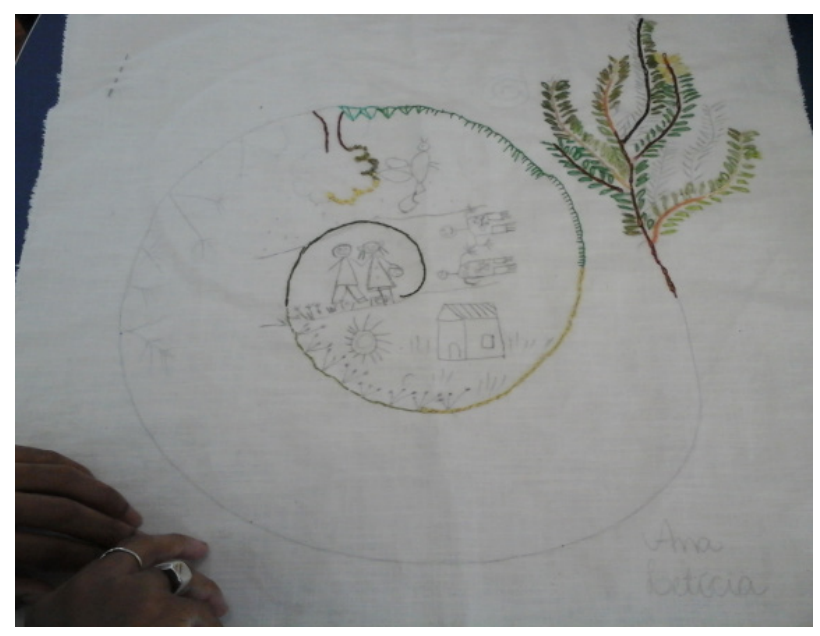

Figura 5

Bordado de Lia inacabado.

Depois que fizemos o curso de bordado com as Dumont, sempre que ia para o Benjamin nos dias da Lia eu vestia uma roupa bordada ou rendada. Lia adorava. Quando me via, parava tudo o que estava fazendo, vinha em minha direção, aproximava-se do bordado ou renda e admirava. Por fim, olhava para mim e dizia bonito em língua de sinais.

Lia não utilizava uma língua para se comunicar. Como salientado acima, o que circulava entre ela e as pessoas com as quais se comunicava era dado pelo movimento e pela observação. Pegávamos na mão dela e íamos fazer algo junto. Ou então ela pegava algo que representasse o que queria fazer ou o que estava pensando e nos mostrava. Foi assim que convidei a Lia para fazer ovos de páscoa em abril e biscoitos de natal no final do ano de 2014 e os fizemos juntas, eu dando os ingredientes e fazendo o movimento de misturar, mexer, amassar, moldar etc. e ela repetindo. Também foi assim que ela participou comigo do curso de bordado livre e, do mesmo modo, me contou sobre um desejo/sonho seu, quando em um dia parou diante de mim e começou a fazer um monte de gestos. Estendeu os braços para frente e direcionados para baixo e fez com eles um meio círculo em volta do seu quadril. Depois deslizou as palmas das mãos em seu tronco do colo até a cintura e tirou da bolsa uma boneca, tipo Barbie, que vestia um vestido rosa de princesa. Para terminar a história apontou o indicador para cima e deu um sopro na pontinha do dedo como quem apaga uma vela. A Hélia estava ao meu lado e me ajudou a ler o que Lia dizia: "Ela está te dizendo que quer uma festa de aniversário de princesa”. Era a língua do corpo!

Depois do curso das Dumont conseguimos nos juntar para bordar umas três vezes, e só. Surgiram dinâmicas no PAAS que levaram Lia para outros caminhos. Apareceu uma professora primária com a intenção de desenvolver alguns experimentos de alfabetização com ela. Aí quando eu chegava ao PAAS para bordar com Lia, a encontrava trabalhando com a professora voluntária. Na tentativa de alfabetização Lia escrevia palavras, juntavas palavras e letras (em português e em Libras) a imagens/figuras e representação de sinais em Libras. Esse experimento de alfabetização da Lia foi aceito pela professora do PAAS com descrença. A mãe, em contrapartida, dizia: "Ela adora escrever, adora. Fica em casa escrevendo letras. Pega um papel e escreve várias letras".

Enquanto a professora voluntária tentava desenvolver seu trabalho de alfabetização, eu ainda consegui ter dois encontros com Lia. Nestes encontros retomei o bordado e ensinei alguns pontos. Avançamos mais um pouquinho, mas fui aceitando o afastamento e entendendo-o como um ciclo que se fechava para em outro momento, quem sabe, se renovar. Os horários de Lia comigo começaram a confluir com os da professora alfabetizadora. Ainda tentei evitar o desvio, mas não adiantou. Então me contentei em ver Lia seguir o fluxo daquele território. Eu parei de bordar com a Lia em meados de outubro e, após a interrupção de nossos trabalhos, nos poucos dias em que me encontrava com ela, ficava observando seus atendimentos com a professora primária. Lia ficou na companhia da professora alfabetizadora por mais algumas semanas e, no meio de novembro, a professora parou com as tentativas de 
alfabetização. O tempo foi passando e eu fui deixando de existir para Lia. O nosso bordado ficou inacabado.

\section{Considerações finais}

Investigar expressões artísticas de pessoas exige uma postura de abertura para o outro, disposição para o encontro e disponibilidade para as práticas e criações com o outro. O princípio da cartografia como método de pesquisa que se constrói no próprio processo de trabalho foi fundamental para a realização das vivências/ experiências/intervenções. A cartografia inicialmente esboçada constituiu-se em caminho/percurso com a parceria dos sujeitos envolvidos no trabalho. Assim, parti das pessoas com as quais queria estar, conviver, junto perceber para criar. Saí dos meus lugares e habitei, junto às pessoas surdocegas, seus familiares e profissionais da área, as fronteiras do perceber, estar e ser o/no mundo desprovido ou diminuído em audiovisualidade. Queria um processo de trabalho em que ressoasse um comum compartilhado (Ranciére, 2005a; 2005b).
A arte é um meio potente de trabalho com pessoas surdocegas, como expressão de seu ser, como comunicação, como ampliação da percepção e entendimento de mundo. É a arte potência para pessoas surdocegas do mesmo modo como o é também para pessoas videntes e ouvintes. E talvez seja a arte, entre mundos tão distintos e ao mesmo tempo tão semelhantes, um dos espaços da experiência humana onde é possível atuar em cima da linha abissal, porque a arte é capaz de ver o lado de cá e o lado de lá da linha (Santos, 2015). Ou como Rancière nos fala quando aborda a repartição e compartilhamento do sensível entrelaçando arte e política e vê as práticas artísticas como formas modelares de ação e distribuição do comum porque elas são “[...] 'maneiras de fazer' que intervêm na distribuição geral das maneiras de fazer e nas suas relações com maneiras de ser e formas de visibilidade" (2005a, p. 17). As artes são caminhos para pensar o futuro para além do que temos, pensar e lutar por aquilo que ainda não está, mas pode vir a estar.

\section{Referências}

Andrade, A. F. (2014). Acessibilidade cultural e surdocegueira: desafios e proposições (Monografia de Pós-Graduação Latu-Sensu). Departamento de Terapia Ocupacional da Universidade Federal do Rio de Janeiro, Rio de Janeiro, RJ, Brasil.

Alvarez, J., \& Passos, E. (2010). Cartografar é habitar um território existencial. In: Passos, E., Kastrup, V., \& Escóssia, L. (Orgs.), Pistas do método da cartografia: Pesquisa-intervenção e produção de subjetividade (pp. 131-149). Porto Alegre, RS: Sulina.

Cader-Nascimento, F. A. A. A., \& Costa, M. P. R. (2010). Descobrindo a surdocegueira: Educação e comunicação. São Carlos, SP: EdUFSCar.

Dewey, J. (2010). Arte como experiência. São Paulo, SP: Martins Fontes.

Giacomini, L., Petersen, M. I. Cambruzzi, R. C., \& Maia, S. R. (Orgs.).(2005). Síndrome de Usher: Série surdocegueira e deficiência múltipla sensorial. São Paulo, SP: Grupo Brasil de Apoio ao Surdocego e ao Múltiplo Deficiente Sensorial.

Keller, H. (2008). A história da minha vida. Rio de janeiro, RJ: José Olympio.

Masini, E. F. S. (2012). Perceber: Raiz do conhecimento. São Paulo, SP: Vetor.

McInnes, J. (1999). A guide to planning and support for individuals who are deafblindness. London: Toronto Buffalo.

Merleau-Ponty, M. (1999). Fenomenologia da percepção. São Paulo, SP: Martins Fontes.

Merleau-Ponty, M. (1980). O olho e o espírito. In: Chauí, M., Aguilar, N. A., \& Moraes, P. S. Maurice Merleau-Ponty: Textos selecionados (pp. 85-111). São Paulo, SP: Abril Cultural.

Passos, E.,\& Kastrup, V. (2014). Cartografar é traçar um plano comum. In: E. Passos, V. Kastrup, \&S. Tedesco. (Orgs.). Pistas do método da cartografia: a experiência da pesquisa e o plano comum (V. 2, pp. 15-41). Porto Alegre, RS: Sulina.

Passos, E., Kastrup, V., \& Escóssia, L. (Orgs.). (2010). Pistas do método da cartografia: Pesquisa-intervenção e produção de subjetividade. Porto Alegre, RS: Sulina.

Rancière, J. (2005a). A partilha do sensível: Estética e política. São Paulo, SP: EXO Experimental. 
Rancière, J. (2005b). Política da arte. Recuperado de http://www.sescsp.org.br/sesc/images/upload/conferencias/206.rtf

Reyes, D. A. (2004). La sordoceguera: Uma discapacidad singular:Madrid: Organización Nacional de Ciegos Españoles.

Santos, B. S. (2007). Para além do pensamento abissal: Das linhas globais a uma ecologia de saberes. Revista Crítica de Ciências Sociais, (78), 3-46.

Santos, B. S. (2002). Para uma sociologia das ausências e uma sociologia das emergências. Revista Crítica de Ciências Sociais, (63), 237-280.

Santos, B. S. (2015). Epistemologias do sul e a descolonização das ciências sociais.(Palestra). Recuperado de: http:// iptv.usp.br/portal/video.action?idItem=30634

Watanabe, D. R., Giacomini, L., \& Maia, S. R. (Org.). (2006). Entrando em contato com as pessoas surdocegas: Formas de comunicação (Vol. 2). São Paulo: Grupo Brasil.

Watanabe, D. R., \&; Maia, S. R. (Org.). (2012). Projeto pontes e travessias: Formação de guia-intérprete. São Paulo: Ahimsa.

Sites visitados:

Deafblind International (DbI): <http:// deafblindinternational.org>

Instituto Benjamin Constant: <http://www.ibc.gov.br>

Nalaga`at Center - http://www.nalagaat.org.il/home.ph

Arheta Ferreira Andrade

Professora de Artes Cênicas do Instituto Benjamin Constant (IBC), Rio de Janeiro - RJ, Brasil. Doutora em Artes Cênicas pela Universidade Federal do Estado do Rio de Janeiro (Unirio), Rio de Janeiro - RJ, Brasil. Mestre em Educação pela Pontifícia Universidade Católica do Rio de Janeiro (PUC-Rio), Rio de Janeiro - RJ, Brasil. Especialista em Acessibilidade Cultural pela Universidade Federal do Rio de Janeiro (UFRJ), Rio de Janeiro - RJ, Brasil. Especialista em Ensino de Arte pela Universidade Federal de Pernambuco (UFPE), Recife - PE. Brasil. Graduada em Artes Cênicas pela UFPE.

E-mail: aretha_andrade@yahoo.com.br

Recebido 28/06/2018

Aprovado 03/07/2018

Received 06/28/2018

Aproved 07/03/2018

Recibido 28/06/2018

Aprobado 03/07/2018

Como citar: Andrade, A. F. (2018). Surdocegueira, Cartografia e Decolonialidade. Psicologia: Ciência e Profissão, 38(3), 595-610. https:// doi.org/10.1590/1982-3703000082018

How to cite: Andrade, A. F. (2018). Deafblindness, Cartography and Decoloniality. Psicologia: Ciência e Profissão, 38(3), 595-610. https:// doi.org/10.1590/1982-3703000082018

Cómo citar: Andrade, A. F. (2018). Sordoceguera, Cartografía y Decolonialidad. Psicologia: Ciência e Profissão, 38(3), 595-610. https:// doi.org/10.1590/1982-3703000082018 